\title{
EFEK SISA KOMPOS SAMPAH KOTA DENGAN BERBAGAI TAKARAN PUPUK BUATAN TERHADAP PERUBAHAN BEBERAPA SIFAT KIMIA REGOSOL DAN PRODUKSI TANAMAN JAGUNG SEMI (Baby Corn)
}

\author{
Ruhaimah. HB ${ }^{1)}$, Syafrimen Yasin ${ }^{1)}$, Novalina ${ }^{2)}$ \\ 1)Staf Pengajar J ur. Tanah F aperta U nand. ${ }^{2)} M$ ahasiswa J urusan Tanah $F$ aperta U nand
}

Abstract

A pot trial about residue effects of compost and commercial fertilizer on Chemical Characteristics of Regosol and Production of Baby Corn for the second planting time. This research was conducted at Greenhouse of Agriculture Faculty and P3IN Laboratory, Andalas University from August to December 2006. Lettuce was the first plant planted on the pot, then it was continued with Baby Corn. This experiment was arranged based on $3 \times 5$ Factorial Randomized design with three replications. The first factor was compost; 0 ton/ha, 5 ton/ha, and 10 ton/ha. The second factor was commercial fertilizer: $0 \%, 25 \%, 50 \%, 75 \%$, and $100 \%$ of recommendation. Based on the research, it was found that the residue of residue interaction with fertilizer influenced to the growth and yield of Baby Corn for the second planting time. From the statistical analysis of the result, it cwas concluded that 5 ton compost/ha (20g compost/pot) was able to increase the chemical charesteristics of Regosol, they were $\mathrm{pH} \mathrm{H}_{2} \mathrm{O}$, KTK, Corganic and $\mathrm{N}$-total. Whereas for $\mathrm{pH} \mathrm{KCL}$, the available-P and basic cations, its valueable measure was started from $5 \mathrm{ton} / \mathrm{ha}$ ( $20 \mathrm{~g} / \mathrm{pot}$ ). For the analysis of plant in the concentration of $\mathrm{N}$ and $\mathrm{P}$, it was taken from the treatment of 4 ton/ha ( $40 \mathrm{~g} / \mathrm{pot})$ by using $100 \%$ fertilizer.

Key word: The Residue E ffect of M anure

\section{PENDAHULUAN}

Semakin meningkatnya kebutuhan lahan dan langkanya lahan pertanian yang subur dan potensial, serta adanya persaingan penggunaan lahan atas sektor pertanian dan sektor non pertanian maka diperlukan adanya upaya pemanfaatan sumber daya alam yang terarah dan efisien. Permasalahan ini menuntut kita untuk dapat memanfaatkan tanah marginal yang produktivitasnya rendah dan memiliki banyak masalah. Salah satu jenis tanah marginal tersebut adalah Regosol.

Secara alami Regosol memiliki banyak masalah dan produktivitas yang rendah. Oleh karena itu, untuk meningkatkan produktivitas Regosol perlu dilakukan input dari luar seperti pemupukan. Pemakaian pupuk buatan secara terus menerus menimbulkan dampak yang tidak baik terhadap lingkungan seperti terjadinya pencemaran lingkungan dan juga dengan dihapusnya subsidi pupuk oleh pemerintah membuat harga pupuk menjadi tinggi. Hal ini menyebabkan biaya produksi menjadi semakin meningkat dan semakin tidak terjangkau oleh petani. Oleh sebab itu sangat perlu dicari alternatif lain dalam mensubsitusi penggunaan pupuk buatan.

Salah satu alternatif untuk mengatasi permasalahan ini adalah dengan menggunakan bahan organik. Penambahan bahan organik kedalam tanah pasir (Regosol) dapat memperbaiki kondisi fisik, kimia dan biologi tanah. Marsono dan Sigit (2002) berpendapat bahwa struktur tanah menjadi lebih baik sehingga pertumbuhan akar tanaman menjadi baik, dapat meningkatkan daya jerap dan daya pegang tanah terhadap air sehingga tersedia bagi tanaman, serta memperbaiki aktivitas kehidupan mikroorganisme tanah.

Sampah kota merupakan salah satu sumber bahan organik. Hasil penelitian Elwasti (2000) menunjukan bahwa kompos banyak mengandung unsur-unsur hara yang dibutuhkan tanaman. Kandungan unsur hara kompos yang berasal dari sampah kota yaitu sebagai 
berikut : N-Total $(0,74 \%), \mathrm{P}_{2} \mathrm{O}_{5}(2,97 \%)$ dan $\mathrm{K}_{2} \mathrm{O}(1,02 \%)$. Dengan kandungan unsur hara yang tinggi tersebut, ternyata kompos sampah kota dapat mengurangi pemakaian pupuk buatan.

Berdasarkan hasil penelitian pertama oleh Tuesdayna (2006) yang melaporkan bahwa pemberian beberapa takaran kompos sampah kota dan pupuk buatan berinteraksi terhadap berat kering tanaman dan angkutan hara $\mathrm{N}$ tanaman, dan belum memperlihatkan pengaruh interaksi terhadap tinggi tanaman, lebar daun terlebar, angkutan hara $\mathrm{P}$ dan $\mathrm{K}$ tanaman serta produksi tanaman Selada. Namun, bagaimana efek sisa dari interaksi sampah kota dengan pupuk buatan untuk penanaman berikutnya belum diketahui sehingga perlu dilakukan penelitian lanjutan.

Berlatar belakang dari informasi tersebut, maka dilakukanlah penelitian dengan judul "Efek Sisa Kompos Sampah Kota dengan Berbagai Takaran Pupuk Buatan Terhadap Perubahan Beberapa Sifat Kimia Regosol dan Produksi Tanaman Jagung Semi (Baby Corn)". Tujuan penelitian ini adalah untuk mempelajari dan mengetahui efek sisa dari kompos sampah kota dengan berbagai takaran pupuk buatan terhadap perubahan beberapa sifat kimia Regosol pada penanaman kedua yang ditanami Jagung Semi (Baby Corn).

\section{METODOLOGI PENELITIAN}

Tanah bekas penanaman pertama diaduk rata agar homogen lalu dimasukan

dalam pot percobaan. Setelah itu diambil $100 \mathrm{~g} /$ pot contoh tanah untuk dianalisis dan dilanjutkan dengan pemupukan dan penanaman. Pupuk Urea diberikan sebelum tanam dan sebagian lagi 30 hari setelah tanam (HST), sedangkan SP-36 dan $\mathrm{KCl}$ diberikan sebelum tanam. Bibit Jagung ditugalkan sebanyak 2 biji/lubang kemudian ditutup dengan tanah. Seminggu kemudian diseleksi dan ditinggalkan satu tanaman yang terbaik untuk tiap lubang.
Pemeliharaan tanaman meliputi penyiraman, penyiangan, serta pencegahan hama penyakit tanaman. Pemanenan dilakukan setelah rambut tongkol sudah mencapai $2-3 \mathrm{~cm}$.

\section{HASIL DAN PEMBAHASAN}

Hasil analisis sifat kemasaman tanah $(\mathrm{pH})$ akibat dari efek sisa kompos sampah kota dengan pupuk buatan setelah panen pertama atau sebelum penanaman kedua disajikan dalam Tabel 1 di bawah.

Berdasarkan hasil yang diperoleh dapat dikemukakan bahwa kompos sampah kota dengan berbagai takaran pupuk buatan masih berpengaruh terhadap $\mathrm{pH}$ tanah. Pada percobaan efek sisa ini ternyata $\mathrm{pH} \mathrm{H}_{2} \mathrm{O}$ untuk masing-masing perlakuan menunjukan perbedaan yang nyata secara statistik terhadap $\mathrm{pH}$ tanah kecuali dibandingkan dengan tanpa pemberian kompos sampah kota.

Dari hasil penelitian dapat dilihat bahwa seiring dengan meningkatnya takaran kompos sampah kota, $\mathrm{pH}$ tanah ini meningkat kecuali untuk perlakuan 5 ton/ha (20 g/pot) sampah kota dengan 50\% rekomendasi pupuk buatan dan 10 ton/ha (40 g/pot) sampah kota dengan 25 rekomendasi pupuk buatan.

Hasil analisis menunjukan bahwa perlakuan yang diberikan pada penanaman pertama masih memberikan efek sisa terhadap penanaman kedua. Ini terlihat dari terjadinya peningkatan $\mathrm{pH} \mathrm{H}_{2} \mathrm{O}$ pada setiap perlakuan. Hal ini sesuai dengan pendapat. Soepardi (1983) yang menyatakan bahwa kation-kation basa yang dihasilkan dari dekomposisi bahan organik dapat meningkatkan $\mathrm{pH}$ larutan tanah bila bahan organik tersebut sudah melapuk dengan sempurna.

Sedangkan untuk $\mathrm{pH} \mathrm{KCl}$ terlihat bahwa pada sisa perlakuan pemberian 5 ton/ha (20g/pot) dan 10 ton/ha (40g/pot) yang dikombinasikan dengan berbagai takaran pupuk buatan menunjukan hasil yang berbeda nyata untuk semua perlakuan. Bila dibandingkan dengan analisis pada penanaman pertama terlihat 
Tabel 1. Efek sisa pemberian kompos sampah kota dan pupuk buatan pada Regosol terhadap $\mathrm{pH}$ $\mathrm{H}_{2} \mathrm{O}, \mathrm{pH} \mathrm{KCl}$ dan $\mathrm{KTK}$ tanah

\begin{tabular}{|c|c|c|c|c|c|c|}
\hline \multirow{3}{*}{ Ciri Tanah } & \multicolumn{6}{|c|}{ Perlakuan } \\
\hline & \multirow{2}{*}{$\begin{array}{l}\text { Kompos } \\
\text { (g/Pot) }\end{array}$} & \multicolumn{5}{|c|}{ Takaran Pupuk Buatan } \\
\hline & & $0 \% \mathrm{R}$ & $25 \% \mathrm{R}$ & $50 \% \mathrm{R}$ & $75 \% \mathrm{R}$ & $100 \% \mathrm{R}$ \\
\hline \multirow{3}{*}{$\begin{array}{c}\mathrm{pH} \mathrm{H}_{2} \mathrm{O} \\
(1: 1)\end{array}$} & 0 & $5,73 \mathrm{bA}$ & $\begin{array}{c}5,70 \\
\mathrm{abAB}\end{array}$ & $\begin{array}{c}5,53 \mathrm{aAB} \\
\mathrm{CD}\end{array}$ & $\begin{array}{c}5,47 \mathrm{aAB} \\
\mathrm{CD}\end{array}$ & $5,57 \mathrm{bABC}$ \\
\hline & 20 & 6,17 aA & $5,93 \mathrm{aAB}$ & $5,43 \mathrm{aD}$ & $5,47 \mathrm{aD}$ & $5,90 \mathrm{bABC}$ \\
\hline & 40 & $5,77 \mathrm{aB}$ & $\begin{array}{c}5,50 \mathrm{bBC} \\
\mathrm{D}\end{array}$ & $\begin{array}{l}5,50 \\
\mathrm{aBCD}\end{array}$ & $5,77 \mathrm{aBC}$ & $6,55 \mathrm{aA}$ \\
\hline \multirow{3}{*}{$\mathrm{pH} \mathrm{KCl} \mathrm{(1:1)}$} & 0 & $4,80 \mathrm{aAB}$ & $4,83 \mathrm{aA}$ & $\begin{array}{l}4,73 \\
\mathrm{aAB}\end{array}$ & $\begin{array}{r}4,5 \\
\mathrm{aABC}\end{array}$ & $4,23 \mathrm{bC}$ \\
\hline & 20 & $4,43 \mathrm{aA}$ & $4,40 \mathrm{abA}$ & $4,67 \mathrm{aA}$ & $4,53 \mathrm{aA}$ & $4,63 \mathrm{aA}$ \\
\hline & 40 & $4,73 \mathrm{aA}$ & $4,80 \mathrm{aA}$ & $4,53 \mathrm{aA}$ & $4,53 \mathrm{aA}$ & $4,83 \mathrm{aA}$ \\
\hline \multirow{3}{*}{ KTK Tanah } & 0 & $12,42 \mathrm{bD}$ & $17,18 \mathrm{bC}$ & $\begin{array}{c}20,60 \\
\mathrm{aAB}\end{array}$ & $2,73 \mathrm{bA}$ & $19,19 \mathrm{aB}$ \\
\hline & 20 & $18,9 \mathrm{aB}$ & $21,96 \mathrm{aA}$ & $16,31 \mathrm{cC}$ & $14,72 \mathrm{cC}$ & $14,52 \mathrm{bC}$ \\
\hline & 40 & $20,43 \mathrm{aB}$ & $\begin{array}{l}15,04 \\
\mathrm{cCD}\end{array}$ & $17,58 \mathrm{bC}$ & $24,07 \mathrm{aA}$ & $17,81 \mathrm{aC}$ \\
\hline
\end{tabular}

Keterangan : $\mathrm{R}=$ rekomendasi

bahwa semua perlakuan sisa dapat meningkatkan $\mathrm{pH} \mathrm{KCl}$ dan menunjukan pengaruh yang sama pada semua perlakuan kecuali pada pemberian tanpa sampah kota.

Pemberian perlakuan bahan organik pada penanaman pertama ternyata masih memberikan efek sisa yang mampu meningkatkan KTK Regosol. Hal ini dapat dilihat pada Tabel 1, dimana pada interaksi kompos 5 ton/ha (20g/pot) dengan 25\% rekomendasi pupuk buatan memberikan pengaruh yang nyata terhadap KTK tanah bila dibandingkan dengan perlakuan lainnya. Peningkatan KTK yang terjadi sebesar 2,7 me/100g bila dibandingkan tanpa pupuk buatan dan 7,44 me/100g jika taraf pupuk buatan ditingkatka Hal ini diduga karena masih adanya bahan organik yang mengalami pelapukan yang berasal dari sumbangan bahan organik dan sisa-sisa akar tanaman pada penanaman pertama dan memiliki kemampuan yang lebih tinggi dalam menjerap dan mempertukarkan kation. Faktor lain juga disebabkan karena adanya peningkatan $\mathrm{pH}$ Regosol pada penanaman kedua. Hal ini sesuai dengan pendapat Hakim et al (1986) bahwa peningkatan nilai KTK tanah dapat terjadi akibat adanya peningkatan $\mathrm{pH}$ tanah.

Hasil analisis C-organik dan N-total tanah pada Tabel 2 memperlihatkan pengaruh yang nyata terhadap C-organik dan $\mathrm{N}$-total tanah. Untuk interaksi kompos sampah kota 5 ton/ha (20g/pot) dengan 25\% rekomendasi pupuk buatan 
Tabel 2. Efek sisa pemberian kompos sampah kota dan pupuk buatan pada Regosol terhadap C-Org dan N-Total tanah.

\begin{tabular}{lcccccc}
\hline & \multicolumn{5}{c}{ Perlakuan } \\
\cline { 2 - 7 } Ciri Tanah & $\begin{array}{l}\text { Kompos } \\
\text { (g/Pot) }\end{array}$ & $0 \% \mathrm{R}$ & $25 \% \mathrm{R}$ & $50 \% \mathrm{R}$ & $75 \% \mathrm{R}$ & $100 \% \mathrm{R}$ \\
\cline { 3 - 7 } & 0 & $0,04 \mathrm{bD}$ & $0,08 \mathrm{bA}$ & $0,04 \mathrm{cD}$ & $0,06 \mathrm{aC}$ & $0,07 \mathrm{aB}$ \\
\multirow{3}{*}{ N-Tanah } & 20 & $0,07 \mathrm{aB}$ & $0,09 \mathrm{aA}$ & $0,04 \mathrm{bC}$ & $0,04 \mathrm{cC}$ & $0,02 \mathrm{bD}$ \\
& 40 & $0,04 \mathrm{bD}$ & $0,04 \mathrm{cBD}$ & $0,06 \mathrm{aB}$ & $0,04 \mathrm{bC}$ & $0,07 \mathrm{aA}$ \\
\hline \multirow{3}{*}{ C-Organik } & 0 & $2,37 \mathrm{bA}$ & $2,40 \mathrm{aA}$ & $2,43 \mathrm{aA}$ & $2,42 \mathrm{aA}$ & $2,73 \mathrm{aA}$ \\
& 20 & $2,82 \mathrm{aA}$ & $2,69 \mathrm{aAB}$ & $1,59 \mathrm{bC}$ & $1,86 \mathrm{bC}$ & $2,64 \mathrm{abAB}$ \\
& 40 & $1,56 \mathrm{cB}$ & $1,73 \mathrm{bB}$ & $1,84 \mathrm{bA}$ & $1,60 \mathrm{bB}$ & $2,29 \mathrm{bA}$ \\
\hline
\end{tabular}

Keterangan : $\mathrm{R}=$ rekomendasi

memperlihatkan pengaruh yang nyata terhadap C-organik jika dibandingkan 50\% rekomendasi pupuk buatan tapi tidak berpengaruh nyata jika dibandingkan tanpa pupuk buatan. Masih meningkatnya Corganik pada penanaman kedua disebabkan karena masih adanya sumbangan bahan organik yang berasal dari sampah kota pada penanaman sebelumnya. Seperti diketahui bahwa sampah kota yang digunakan sebelumnya mengandung $\mathrm{C}$ sebesar $35,76 \%$. Meningkatnya kandungan $\mathrm{N}$-total tanah juga berasal dari sumbangan bahan organik pada penanaman pertama dan didukung oleh aktivitas mikroorganisme tanah. Hal ini sesuai dengan pendapat Soepardi (1983), bahwa semakin banyak bahan organik yang diberikan kedalam tanah maka semakin aktif mikroorganisme memineralisasi unsur hara dari bahan organik tersebut.

Masih tingginya kandungan Corganik dan N-total tanah disebabkan karena bahan organik pada penanaman pertama telah melapuk dengan sempurna. Pendapat ini didukung oleh Sutidjo (1986) yang menyatakan bahwa pupuk organik mempunyai reaksi lambat karena harus mengalami dekomposisi terlebih dahulu serta mempunyai efek residu karena itu ketersediaan haranya berjalan lambat.

Masih tingginya kandungan Ptersedia tanah juga erat hubungannya dengan bahan organik yang diberikan pada penanaman pertama. Bahan organik yang diberikan telah terdekomposisi lebih lanjut sehingga $\mathrm{P}$ lebih tersedia dalam tanah.

Tabel 3. Efek sisa pemberian kompos sampah kota dan pupuk buatan pada Regosol terhadap Ptersedia tanah

\begin{tabular}{ccccccc}
\hline & \multicolumn{5}{c}{ Takaran Pupuk Buatan } & \\
\cline { 2 - 6 } $\begin{array}{l}\text { Kompos } \\
\text { (g/Pot })\end{array}$ & $0 \% \mathrm{R}$ & $25 \% \mathrm{R}$ & $50 \% \mathrm{R}$ & $75 \% \mathrm{R}$ & $100 \% \mathrm{R}$ & Rata-rata \\
\hline 0 & 27,22 & 31,89 & 26,83 & 31,11 & 25,56 & $28,52 \mathrm{a}$ \\
\hline 20 & 26,14 & 31,68 & 34,27 & 31,34 & 29,23 & $30,53 \mathrm{a}$ \\
\hline 40 & 26,47 & 34,98 & 31,15 & 25,05 & 31,60 & $29,85 \mathrm{a}$ \\
\hline Rata-rata & $26,61 \mathrm{~B}$ & $32,85 \mathrm{~A}$ & $30,75 \mathrm{~A}$ & $30,74 \mathrm{~A}$ & $28,79 \mathrm{AB}$ & 29,63 \\
\hline
\end{tabular}

Keterangan : $\mathrm{R}=$ rekomendasi 
Ketersediaan kation-kation basa seperti $\mathrm{K}, \mathrm{Ca}, \mathrm{Mg}$ dan $\mathrm{Na}$ saling berhubungan erat. Kation-kation ini secara bersama-sama menempati posisi pertukaran kation pada koloid tanah. Jika salah satu unsur didalam tanah sangat melimpah maka ketersediaan basa yang lain akan menurun (Novizan, 2005).

Hasil analisis yang diperoleh untuk kation-kation basa pada penanaman kedua terlihat pada Tabel 4 dibawah. Dari Tabel 4 terlihat bahwa interaksi antara sampah kota 10 ton/ha (40g/pot) dengan pupuk buatan 50\% rekomendasi memperlihatkan hasil yang peningkatan kation K-dd yang lebih tinggi jika dibandingkan dengan 5 ton/ha (20g/pot) sampah kota dengan tanpa pupuk buatan.

Demikian juga untuk Ca-dd, Mg-dd dan Na-dd menunjukan peningkatan dari penanaman pertama. Jika dilihat dari hasil ternyata kompos sampah kota dengan pupuk buatan masih mampu meningkatkan $\mathrm{Ca}, \mathrm{Mg}$ dan Na dapat dipertukarkan. Hal ini menandakan masih adanya efek sisa dari perlakuan sebelumnya. Peningkatan K, Mg, $\mathrm{Ca}$ dan $\mathrm{Na}$ dapat dipertukarkan setelah penanaman pertama ini disebabkan oleh sumbangan kation-kation hasil dekomposisi dari kompos sampah kota yang diberikan. Hal ini diutarakan oleh Soegiman (1982) bahwa hasil dari pelapukan bahan organik banyak mengandung kation-kation $\mathrm{Ca}, \mathrm{Mg}$, $\mathrm{K}$ dan $\mathrm{Na}$ tersedia bagi tanaman. Hal ini sejalan dengan pendapat Rinsema (1986) yang menyatakan, bahan organik mengandung sejumlah unsur hara diantaranya $\mathrm{Ca}, \mathrm{Mg}, \mathrm{K}$ dan $\mathrm{Na}$ disebabkan oleh pengaruh asam organik hasil perombakan bahan organik.

Sedangkan hasil pengamatan untuk tanaman dilihat dari pengamatan tinggi tanaman dan analisis kadar hara N, P dan K. Dari hasil analisis statistik terhadap

Tabel 4. Efek sisa pemberian kompos sampah kota dan pupuk buatan pada Regosol terhadap Ptersedia tanah.

\begin{tabular}{ccccccc}
\hline & \multicolumn{5}{c}{ Perlakuan } \\
\cline { 2 - 7 } Ciri & Kompos & \multicolumn{5}{c}{ Takan Pupuk Buatan } \\
\cline { 2 - 7 } & \begin{tabular}{l} 
(g/Pot) \\
\cline { 3 - 7 }
\end{tabular} & $0 \% \mathrm{R}$ & $25 \% \mathrm{R}$ & $50 \% \mathrm{R}$ & $75 \% \mathrm{R}$ & $100 \% \mathrm{R}$ \\
\hline \multirow{2}{*}{ K-dd } & 0 & $0,29 \mathrm{aBC}$ & $0,31 \mathrm{aABC}$ & $0,19 \mathrm{bC}$ & $0,23 \mathrm{aAB}$ & $0,43 \mathrm{aA}$ \\
& 20 & $0,32 \mathrm{aA}$ & $0,22 \mathrm{aA}$ & $0,29 \mathrm{abA}$ & $0,27 \mathrm{abA}$ & $0,24 \mathrm{cA}$ \\
& 40 & $0,21 \mathrm{aAB}$ & $0,22 \mathrm{aAB}$ & $0,34 \mathrm{aA}$ & $0,20 \mathrm{bB}$ & $0,25 \mathrm{bAB}$ \\
\hline \multirow{2}{*}{ Na-dd } & 0 & $0,15 \mathrm{bCD}$ & $0,58 \mathrm{aA}$ & $0,42 \mathrm{aB}$ & $0,3 \mathrm{cB}$ & $0,28 \mathrm{aBC}$ \\
& 20 & $0,8 \mathrm{bA}$ & $0,17 \mathrm{bC}$ & $0,50 \mathrm{aB}$ & $0,54 \mathrm{bB}$ & $0,17 \mathrm{aC}$ \\
& 40 & $0,43 \mathrm{aA}$ & $0,12 \mathrm{bB}$ & $0,19 \mathrm{bB}$ & $0,38 \mathrm{aA}$ & $0,17 \mathrm{abB}$ \\
\hline \multirow{2}{*}{ Ca-dd } & 0 & $1,13 \mathrm{aB}$ & $1,20 \mathrm{bAB}$ & $1,21 \mathrm{abAB}$ & $1,44 \mathrm{abA}$ & $1,32 \mathrm{bAB}$ \\
& 20 & $1,31 \mathrm{aC}$ & $1,58 \mathrm{aAB}$ & $1,25 \mathrm{aC}$ & $1,24 \mathrm{bC}$ & $1,67 \mathrm{aA}$ \\
& 40 & $1,29 \mathrm{aBC}$ & $1,25 \mathrm{bBCD}$ & $1,04 \mathrm{bD}$ & $1,55 \mathrm{aA}$ & $1,38 \mathrm{bAB}$ \\
\hline \multirow{2}{*}{ Mg-dd } & 0 & $0,39 \mathrm{aA}$ & $0,36 \mathrm{bA}$ & $0,39 \mathrm{aA}$ & $0,46 \mathrm{bA}$ & $0,40 \mathrm{bA}$ \\
& 20 & $0,43 \mathrm{aAC}$ & $0,48 \mathrm{aAB}$ & $0,39 \mathrm{aAC}$ & $0,41 \mathrm{bAC}$ & $0,49 \mathrm{aBC}$ \\
& 40 & $0,40 \mathrm{aC}$ & $0,44 \mathrm{aB}$ & $0,35 \mathrm{aD}$ & $0,54 \mathrm{aA}$ & $0,43 \mathrm{abBC}$ \\
\hline
\end{tabular}

Keterangan : $\mathrm{R}=$ rekomendasi 
tinggi tanaman tidak memberikan pengaruh yang berbeda nyata untuk semua perlakuan. Namun secara kuantitatif terjadi peningkatan tinggi tanaman seiring dengan peningkatan takaran kompos sampah kota. Tidak terdapatnya perbedaan tinggi tanaman jagung semi mungkin disebabkan kebutuhan hara $\mathrm{N}$ untuk menunjang pertumbuhan tinggi telah terpenuhi akibat dari pemberian bahan organik dan pupuk buatan sewaktu penanaman sebelumnya. Hal ini sesuai dengan pendapat Gardner, Pearce dan Mitchel (1991) menyatakan bahwa peningkatan dosis pupuk tidak lagi memberikan respon terhadap pertumbuhan dan hasil tanaman jika kebutuhan tanaman jika kebutuhan unsur hara tanaman tersebut telah terpenuhi. Sedangkan untuk analisis kadar hara N-tanaman disajikan dalam Tabel 5.

Hasil analisis kadar hara N-tanaman menunjukan hasil yang berbeda nyata terhadap hara N. Hal ini berhubungan dengan membaiknya kesuburan tanah akibat efek sisa yang ditimbulkan dari pemberian kompos dan pupuk buatan pada penanaman sebelumnya. Hal ini sesuai dengan hasil penelitian Jannah, Rahmi dan Sumedi cit Sutanto (2002) yang menyatakan bahwa unsur hara yang terkandung dalam bahan organik baru dapat tersedia bagi tanaman setelah mengalami proses dekomposisi. Unsur $\mathrm{N}$ dan unsur lain yang dikandung dilepaskan secara perlahan-lahan.

Tabel 5. Efek sisa pemberian kompos sampah kota dan pupuk buatan pada Regosol terhadap kadar hara N-tanaman

\begin{tabular}{cccccc}
\multirow{2}{*}{$\begin{array}{l}\text { Kompos } \\
\text { (g/Pot) }\end{array}$} & $0 \% \mathrm{R}$ & $25 \% \mathrm{R}$ & $50 \% \mathrm{R}$ & $75 \% \mathrm{R}$ & $100 \% \mathrm{R}$ \\
\cline { 2 - 6 } & $1,94 \mathrm{aB}$ & $2,35 \mathrm{aAB}$ & $2,55 \mathrm{aAB}$ & $2,99 \mathrm{aA}$ & $2,02 \mathrm{bB}$ \\
\hline 0 & $2,24 \mathrm{aA}$ & $2,44 \mathrm{aA}$ & $2,24 \mathrm{aA}$ & $2,04 \mathrm{bA}$ & $2,78 \mathrm{aA}$ \\
\hline 20 & $2,24 \mathrm{aA}$ & $2,36 \mathrm{aA}$ & $2,19 \mathrm{aA}$ & $2,19 \mathrm{bA}$ & $2,52 \mathrm{abA}$
\end{tabular}

Keterangan : $\mathrm{R}$ = rekomendasi

Tabel 6. Efek sisa pemberian kompos sampah kota dan pupuk buatan pada Regosol terhadap kadar hara P-tanaman

\begin{tabular}{ccccccc}
\hline \multirow{2}{*}{$\begin{array}{c}\text { Kompos } \\
\text { g/Pot })\end{array}$} & \multicolumn{5}{c}{ Takaran Pupuk Buatan } & \multirow{2}{*}{ Rata-rata } \\
\cline { 2 - 5 } & $0 \% \mathrm{R}$ & $25 \% \mathrm{R}$ & $50 \% \mathrm{R}$ & $75 \% \mathrm{R}$ & $100 \% \mathrm{R}$ & \\
\hline 0 & 0,268 & 0,234 & 0,213 & 0,246 & 0,213 & $0,235 \mathrm{a}$ \\
\hline 20 & 0,203 & 0,278 & 0,194 & 0,257 & 0,219 & $0,230 \mathrm{a}$ \\
\hline 40 & 0,234 & 0,189 & 0,173 & 0,175 & 0,354 & $0,235 \mathrm{a}$ \\
\hline Rata-rata & $0,235 \mathrm{~A}$ & $0,234 \mathrm{~A}$ & $0,193 \mathrm{~A}$ & $0,226 \mathrm{~A}$ & $0,262 \mathrm{~A}$ & 0,230
\end{tabular}

Keterangan : $\mathrm{R}=$ rekomendasi 
Tabel 7. Efek sisa pemberian kompos sampah kota dan pupuk buatan pada Regosol terhadap kadar hara K-tanaman

\begin{tabular}{rrrrrr}
\hline \multirow{2}{*}{$\begin{array}{c}\text { Kompos } \\
\text { (g/Pot) }\end{array}$} & $0 \% \mathrm{R}$ & $25 \% \mathrm{R}$ & $50 \% \mathrm{R}$ & $75 \% \mathrm{R}$ & $100 \% \mathrm{R}$ \\
\cline { 2 - 6 } 0 & $2,92 \mathrm{aA}$ & $2,06 \mathrm{aB}$ & $2,10 \mathrm{aAB}$ & $2,19 \mathrm{aAB}$ & $2,08 \mathrm{aAB}$ \\
\hline 20 & $1,99 \mathrm{bA}$ & $2,17 \mathrm{aA}$ & $2,02 \mathrm{aA}$ & $2,25 \mathrm{aA}$ & $2,06 \mathrm{aA}$ \\
\hline 40 & $2,15 \mathrm{bA}$ & $2,33 \mathrm{aA}$ & $2,12 \mathrm{aA}$ & $2,18 \mathrm{aA}$ & $2,19 \mathrm{aA}$ \\
\hline
\end{tabular}

Keterangan : $\mathrm{R}=$ rekomendasi

Untuk hasil analisis kadar P-tanaman menunjukan hasil yang berbeda tidak nyata untuk smua perlakuan. Hal ini mungkin disebabkan karena rendahnya unsur $\mathrm{P}$ yang dikandung oleh sampah kota yaitu $0,49 \%$. Namun bila dilihat secara angka pemberian5 ton/ha (20g/pot) sampah kota dengan $25 \%$ rekomendasi pupuk buatan dapat meningkatkan kadar hara P-tanaman sebesar $0,075 \%$ bila dibandingkan tanpa pupuk buatan namun peningkatan ini tidak begitu berarti. Lebih jelasnya kadar hara P-tanaman jagung semi terlihat pada Tabel 6.

Untuk analsis kadar hara K-tanaman menunjukan adanya interaksi sampah kota dengan faktor pupuk buatan pada penanaman kedua. Hal ini dapat dilihat pada Tabel 7 berikut.

Masih adanya efek sisa kompos sampah kota dengan pupuk buatan berhubungan dengan kandungan K-dd tanah. Selain itu penambahan pupuk $\mathrm{K}$ juga dapat meningkatkan serapan hara bagi tanaman karena adnya penambahan pupuk $\mathrm{KCl}$ akan mengakibatkan $\mathrm{K}$ lebih tersedia di dalam tanah. Disamping itu $\mathrm{K}$ penting dalam menambah ketahanan tanaman terhadap penyakit dan memperkuat batang sehingga tidak mudah rebah serta merangsang pertumbuhan akar sehingga dapat meningkatkan daya serapan hara bagi tanaman (Soepardi, 1983).

\section{DAFTAR PUSTAKA}

Brady. Bharata Karya Aksara. Jakarta. 788 halaman.

Elwasti, Y.2000. Penggunaan campuran abu janjang, sludge dan kompos sebagai pupuk alternatif tanaman kedelai. Skripsi Sarjana Fakultas Pertanian Universitas Andalas Padang. 62 halaman.

Hakim, N., M.Y.Nyakpa, A.M.Lubis, S.G. Nugroho, M. A. Diha, G.B. Hong dan H.H. Bailey. 1986. Dasar-dasar Ilmu Tanah. Universitas Lampung. Lampung.488 halaman.

Gardner, P. F. Peace. B. R. And Mitchell. L, R. 1991. Fisioloogi Tanaman Budidaya. Alih bahasa oleh Susilo, $\mathrm{H}$ dari Physiology of Crop Plant. 1985. Universitas Indonesia Press. Jakarta.

Marsono dan Sigit, P. 2002. Pupuk Akar, Jenis dan Aplikasi. Penebar Swadaya. Jakarta. 114 halaman.

Novizan. 2002. Petunjuk Pemupukan yang Efektif. Agromedia Pustaka. 114 halaman.

Soegiman.1982. Ilmu Tanah Terjemaahan dari The Nature and Properties of Soil by H.O. Buckman dan N.C. 
Soepardi, G. 1983. Sifat dan ciri tanah. Departemen Ilmu Tanah, Fakultas Pertanian IPB. Bogor.59 halaman.

Sugihartina. 1993. Pengaruh Berbagai Takaran Pupuk Kandang terhadap Sifat Kimia Tanah untuk Tanaman Jagung (Zea mays, L) di Lahan Kritis. Skripsi Fakultas Pertanian Universitas Andalas. Padang. 57 halaman.
Sutanto, R. 2002. Penerapan Pertanian Organik Pemasyarakatan dan Pengembangannya. Kanisius. Yogyakarta. 219 halaman.

Sutidjo, D. 1986. Buku Kuliah Pengantar Sistem Produksi Tanaman Agronomi Jurusan BDP, Fakultas Pertanian. IPB. Bogor.135 halaman 